\title{
Oncostatin M Production by Blood and Alveolar Neutrophils during Acute Lung Injury
}

\author{
Alain Grenier, Danièle Combaux, Jean Chastre, Marie Anne Gougerot-Pocidalo, \\ Claude Gibert, Monique Dehoux, and Sylvie Chollet-Martin*
}

Service de Biochimie (AG), CHI Le Raincy-Montfermeil, Montfermeil; and INSERM U 479 and Service d'Hématologie et d'Immunologie (AG, MAG-P, SC-M), INSERM U 408 and Service de Biochimie A (AG, MD), and Service de Réanimation Médicale (DC, JC, CG), CHU Xavier Bichat, Paris, France

SUMMARY: Polymorphonuclear neutrophils (PMN) are involved in the pathogenesis of acute lung injury (ALI), secreting numerous mediators such as proteases, reactive oxygen species, and cytokines. Because we had recently observed the ability of normal human PMN to degranulate and synthesize oncostatin M (OSM), an IL-6-family cytokine, we quantified OSM production ex vivo by highly purified blood and alveolar PMN from 24 ventilated patients with ALI, including some patients with severe pneumonia. Most of the patients had no detectable OSM in plasma, and OSM production by cultured blood PMN was similar to that of healthy controls. However, OSM was present in bronchoalveolar lavage (BAL) fluid supernatant, with significantly higher levels during pneumonia. In addition, alveolar OSM levels correlated with the number of PMN obtained by BAL, suggesting that PMN are an important source of OSM within the alveoli. Indeed, purified alveolar PMN from all of the patients, especially those with pneumonia, strongly produced OSM. Interestingly, in the latter patients, alveolar PMN always produced more OSM than autologous blood PMN. These results document the functional duality of PMN in ALI by showing the participation of PMN in the modulation of lung inflammation. (Lab Invest 2001, 81:133-141).

$P$ ulmonary infiltration by polymorphonuclear neutrophils $(P M N)$ is frequently observed during acute lung injury (ALI) (Artigas et al, 1998). Interest in the pathogenetic mechanisms of ALI has focused in recent years on interactions between PMN and cytokines (Pittet et al, 1997). In particular, several reports from our group and others have indicated that circulating and alveolar PMN are activated and that proinflammatory cytokines may play an active role in this process (Chollet-Martin et al, 1992, 1996; Martin et al, 1991). Activated PMN can damage the lung through several potential mechanisms, including the release of proteases, cytokines, and reactive oxygen species (ROS), but recent data also suggest a role for PMN in the modulation of inflammation and tissue repair (Boutten et al, 1998; Donnelly et al, 1995). In particular, we showed that blood PMN were able to release oncostatin M (OSM) through a two-step mechanism that involves degranulation followed by de novo protein synthesis, leading to rapid and sustained OSM secretion at inflammatory sites (Grenier et al, 1999). OSM, an IL-6-family cytokine, is a potent inducer of several antiproteases, including $\alpha 1$-antitrypsin $(\alpha 1$ AT), in both hepatocytes and lung epithelial cells (Cichy et al, 1998a; Sallenave et al, 1997). OSM could

Received July 7, 2000.

* Both MD and SC-M equally contributed to the management of the work.

Address reprint requests to: Dr. Sylvie Chollet-Martin, Service d'Hématologie et d'Immunologie, CHU Xavier Bichat, rue Henri Huchard, 75018 Paris, France.E-mail: sylvie.martin@bch.ap-hop-paris.fr thus participate in local antiprotease defenses within the lung. Moreover, in a recent study using a model of acute inflammatory disease, in vivo administration of OSM reduced inflammation and mortality (Wallace et al, 1999). Because high levels of OSM have been found recently in bronchoalveolar lavage (BAL) fluid from patients with severe pneumonia, but not from healthy volunteers (Dehoux et al, 1999), we postulated that alveolar PMN might play a role in this local OSM synthesis.

The aim of this study was to quantify OSM production by blood and alveolar PMN isolated from patients with $\mathrm{ALI}$, and to compare patients with and without severe pneumonia. Systemic and local OSM production was compared in each patient, and correlations with clinical parameters were sought. Our data suggest that, in addition to their well-documented deleterious effects on lung structures, PMN can also modulate the inflammatory response by synthesizing OSM and thereby play a new role in recovery from ALI.

\section{Results}

\section{Patients}

The clinical characteristics of the 24 patients at the time of the assays are listed in Table 1. The primary indications for mechanical ventilation in the patients with pneumonia $(n=15)$ were postoperative heart failure $(n=9)$, postoperative respiratory failure $(n=1)$, severe community-acquired pneumonia $(n=2)$, hemorrhagic shock ( $n=1)$, postoperative septic syndrome $(n=1)$, and neurologic emergency $(n=1)$. In the 
Table 1. Clinical Characteristics of the Patients with Acute Lung Injury

\begin{tabular}{|c|c|c|}
\hline & $\begin{array}{l}\text { Without pneumonia } \\
\qquad(n=9)\end{array}$ & $\begin{array}{l}\text { With pneumonia } \\
\quad(n=15)\end{array}$ \\
\hline Age, yr & $58 \pm 5.5$ & $71 \pm 2.5$ \\
\hline Duration of ventilation, $d$ & $15 \pm 3$ & $21 \pm 6$ \\
\hline SAPS & $38 \pm 4$ & $43 \pm 5$ \\
\hline Organ dysfunction, $n$ & 2.3 & 2.8 \\
\hline Lung injury score & 1.4 & 1.6 \\
\hline Tidal volume $(\mathrm{ml} / \mathrm{kg})$ & $7.7 \pm 0.4$ & $7.6 \pm 0.4$ \\
\hline PEEP $\left(\mathrm{cm} \mathrm{H}_{2} \mathrm{O}\right)$ & 0 , except 1 patient $=6$ & 0 , except 1 patient $=8$ \\
\hline $\mathrm{FiO}_{2}$ & $0.45 \pm 0.06$ & $0.51 \pm 0.05$ \\
\hline $\mathrm{PaO}_{2} / \mathrm{FiO}_{2}(\mathrm{mmHg})$ & $229 \pm 25$ & $211 \pm 22$ \\
\hline \multicolumn{3}{|c|}{ Number of patients with septic shock: } \\
\hline —with bacteremia & 0 & 3 \\
\hline —without bacteremia & 2 & 2 \\
\hline Mortality rate (\%) & 60 & 67 \\
\hline
\end{tabular}

SAPS, simplified acute physiology score; PEEP, positive end-expiratory pressure.

Values are means \pm SEM.

patients without pneumonia $(n=9)$, the primary indications for ventilation were postoperative septic syndrome $(n=3)$, heart failure $(n=3)$, neurologic emergency $(n=1)$, respiratory failure $(n=1)$, and cardiac arrest $(n=1)$. In the 15 patients with pneumonia, protected specimen brushing and/or BAL fluid culture yielded a single organism in nine cases: (Pseudomonas aeruginosa $=1$, Haemophilus influenzae $=1$, Staphylococcus aureus $=2$, Proteus mirabilis $=2$, Escherichia coli $=1$, Acinetobacter baumannii $=1$, Streptococcus pneumonia $=1$ ) and two organisms in six cases: (Staphylococcus aureus $=4$, Streptococcus oralis $=1$, Streptococcus viridans $=1$, Morganella morganii $=1$, Haemophilus influenzae $=1$, Proteus mirabilis $=1$, Neisseria $=1$, Pseudomonas aeruginosa $=1$, Stenotrophomonas maltophilia $=1$ ).

Tidal volumes, $\mathrm{FiO}_{2}$ values, and lung injury scores were similar in the two groups. Only one patient in each patient group had positive end-expiratory pressure (PEEP) (Table 1). The mortality rates are listed in Table 1.

\section{BAL Fluid Cytology}

Table 2 shows the total and differential BAL fluid cell counts in the two groups of patients. The total number of cells was significantly higher in the patients with pneumonia than in the patients without pneumonia ( $p$ $<0.05)$. The percentage and absolute number of neutrophils were significantly higher in BAL fluid from patients with pneumonia than from patients without pneumonia $(p<0.05)$. Macrophages represented less than half the cells in BAL fluid from the two groups of patients, and their absolute number was similar in the two groups.

\section{OSM Levels in BAL Fluid Supernatant}

As shown in Figure 1, OSM was detected in the BAL fluid supernatants from all but two of the patients without pneumonia. In these two patients, OSM values were assigned the detection limit $(2.1 \mathrm{pg} / \mathrm{ml})$. The concentration of OSM was significantly higher in BAL fluid from patients with pneumonia than from patients without pneumonia $(339 \pm 109 \mathrm{pg} / \mathrm{ml}$ versus $49 \pm 13$ $\mathrm{pg} / \mathrm{ml}$, respectively; $p<0.05)$.

\section{Plasma OSM Levels}

In contrast with the elevated OSM concentrations in BAL fluid supernatants, OSM was only detectable in the plasma of four patients with pneumonia $(55,22$,

Table 2. Total and Differential Bronchoalveolar Lavage Fluid Cell Counts in Patients with Acute Lung Injury

\begin{tabular}{|c|c|c|}
\hline & $\begin{array}{l}\text { Without pneumonia } \\
\qquad(n=9)\end{array}$ & $\begin{array}{l}\text { With pneumonia } \\
\qquad(n=15)\end{array}$ \\
\hline Total cells $\left(\times 10^{3} / \mathrm{ml}\right)$ & $643 \pm 334$ & $1808 \pm 623^{*}$ \\
\hline Macrophages (\%) & $47 \pm 11$ & $20 \pm 4^{\star}$ \\
\hline$\left(\times 10^{3} / \mathrm{ml}\right)$ & $230 \pm 137$ & $308 \pm 148$ \\
\hline Neutrophils (\%) & $48 \pm 11$ & $78 \pm 4^{\star}$ \\
\hline$\left(\times 10^{3} / \mathrm{ml}\right)$ & $462 \pm 218$ & $1482 \pm 553^{*}$ \\
\hline Lymphocytes (\%) & $4 \pm 1$ & $2 \pm 1$ \\
\hline$\left(\times 10^{3} / \mathrm{ml}\right)$ & $30 \pm 18$ & $20 \pm 11$ \\
\hline
\end{tabular}

Values are means \pm SEM.

${ }^{\star} p<0.05$ versus patients without pneumonia. 


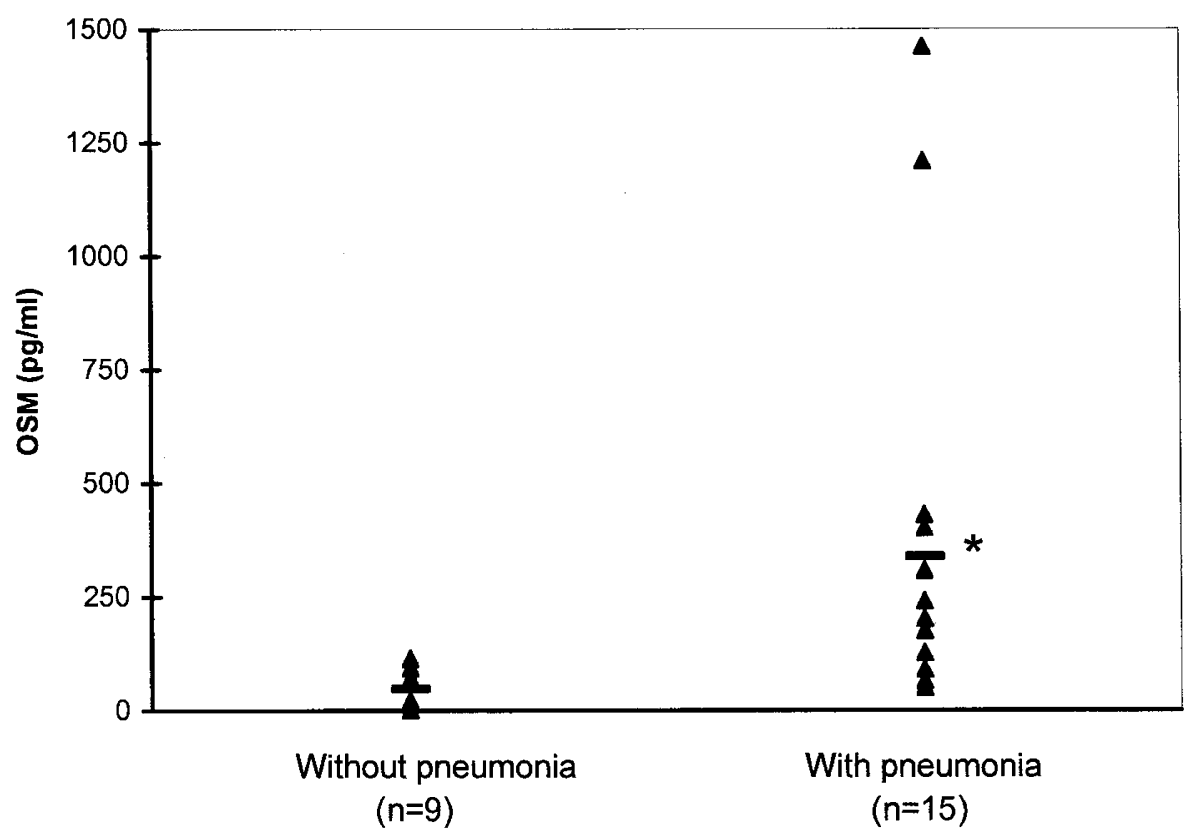

Figure 1.

Mean and individual oncostatin M (OSM) concentrations in bronchoalveolar lavage (BAL) fluid from the two groups of patients with acute lung injury (ALI). ${ }^{*} p<$ 0.05 versus patients without pneumonia.

39, and $19 \mathrm{pg} / \mathrm{ml}$ ), one patient without pneumonia (11 $\mathrm{pg} / \mathrm{ml}$ ), and none of the healthy controls. Interestingly, the patients with detectable plasma OSM all had septic shock.

\section{Immunocytochemical Detection of OSM in BAL Cells}

Immunocytochemistry showed the presence of intracellular OSM in both alveolar PMN and macrophages in BAL cell cytospin preparations (Fig. 2). In the overall patient population, OSM concentrations in BAL fluid supernatants showed a strong positive correlation with the absolute number of PMN (but not with macrophages or lymphocytes) in $\mathrm{BAL}$ fluid ( $\rho=0.74, p<$ 0.001) (Fig. 3). This argues for a major participation of PMN in OSM production but does not exclude a role for macrophages.

\section{Spontaneous Ex Vivo OSM Secretion by Blood and Alveolar PMN}

Spontaneous OSM secretion by blood and alveolar PMN after 18 hours of culture was compared in the two groups. As shown in Figure 4, blood PMN displayed normal spontaneous OSM secretion in the two groups of patients $\left(114 \pm 25 \mathrm{pg} / \mathrm{ml} / 10^{7} \mathrm{PMN}\right.$ in patients without pneumonia, $129 \pm 36 \mathrm{pg} / \mathrm{ml} / 10^{7} \mathrm{PMN}$ in patients with pneumonia), on the basis of healthy control values $\left(119 \pm 10 \mathrm{pg} / \mathrm{ml} / 10^{7} \mathrm{PMN}\right)$. Spontaneous OSM production by alveolar PMN was significantly higher in the patients with pneumonia than in the patients without pneumonia $\left(614 \pm 133 \mathrm{pg} / \mathrm{ml} / 10^{7}\right.$ PMN versus $174 \pm 77 \mathrm{pg} / \mathrm{ml} / 10^{7} \mathrm{PMN}, p<0.01$ ) (Fig. 4). Interestingly, OSM production by alveolar PMN was significantly higher than that by autologous peripheral blood PMN in patients with pneumonia (paired comparisons, $p<0.01$ ). Moreover, in the overall patient population, the OSM concentration in BAL fluid supernatants correlated with the capacity of alveolar PMN to produce OSM ex vivo $(\rho=0.54, p<$ 0.05).

\section{Correlations between OSM Concentrations and Clinical Parameters}

There was a trend toward a correlation between OSM levels in $\mathrm{BAL}$ fluid and the $\mathrm{PaO}_{2} / \mathrm{FiO}_{2}$ ratio $(p=0.07)$ but not the simplified acute physiology score (SAPS). Neither of these latter parameters correlated with plasma OSM concentrations or OSM production by blood PMN (data not shown). None of the OSM data correlated with outcome, the presence of septic shock, or the bacterial type and density. Finally, OSM values were not significantly different in survivors and nonsurvivors.

\section{Discussion}

This study identifies a cellular source for the high OSM concentrations found in the alveolar spaces of patients with ALI. Moreover, purified alveolar PMN from patients with pneumonia spontaneously produced high levels of OSM ex vivo, with values always higher than those obtained with autologous blood PMN.

All of the patients were ventilated using a lungprotective strategy with similar low tidal volumes to reduce the mechanical ventilation-induced inflammatory response (ARDS Network, 2000; Ranieri et al, 1999). We can thus assume that the differences in OSM levels observed among the patients were not related to differences in tidal volumes. 


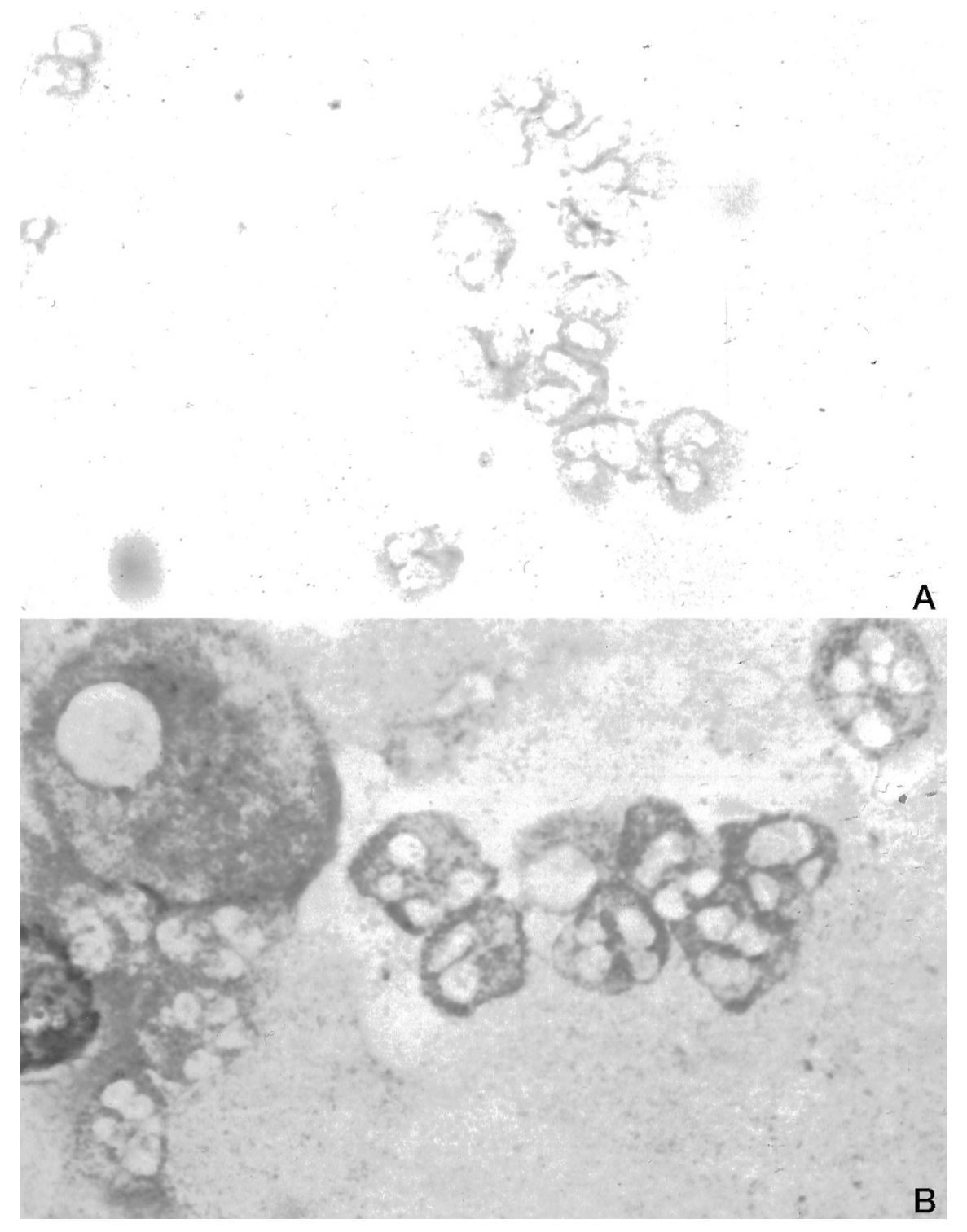

Figure 2.

Immunocytochemical detection of OSM in BAL cells. A, Negative control. No staining was observed with an isotypic control immunoglobulin. B, Intracellular red staining was observed in both polymorphonuclear neutrophils (PMN) (right) and macrophages (left), using a specific polyclonal antiOSM antibody. Cytospin preparations were examined with a light microscope at $\times 100$ magnification.

It has recently been reported that OSM is detectable in the BAL fluid of patients with nosocomial pneumonia but not that of healthy controls (Dehoux et al, 1999). We confirm these data in patients with severe pneumonia, and extend them to ALI patients without pneumonia. Two other cytokines also belonging to the IL-6 family have previously been found at high concentrations in BAL fluid from patients with ALI, namely leukemia inhibitory factor (Jorens et al, 1996) and IL-6 (Chollet-Martin et al, 1996). We found that OSM concentrations were significantly higher in BAL fluid from patients with pneumonia than from ALI patients free of pneumonia. It is noteworthy that the amount of OSM correlated strongly with the absolute number of PMN in BAL fluid. Because our group has recently observed the capacity of human blood PMN to produce and release OSM (Grenier et al, 1999), we think these cells may be a major source of OSM within the alveoli.
Other cells potentially contributing to this local OSM production include monocytes/macrophages (Malik et al, 1989), as shown by positive staining of both PMN and macrophages on BAL cell cytospin preparations. In contrast to PMN, we found that absolute macrophage counts did not correlate with OSM concentrations in BAL fluid. Although we did not exclude a role of alveolar macrophages in local OSM production, the aim of this work was to focus on the role of PMN, which are of major importance in the pathogenesis of ALI.

PMN are thus a potentially important local source of OSM during pulmonary inflammation, through a twostep mechanism we have previously observed in blood PMN (Grenier et al, 1999). This mechanism was confirmed here, albeit on a limited number of alveolar PMN samples, owing to the difficulty of obtaining sufficient PMN from BAL fluid (not shown). 


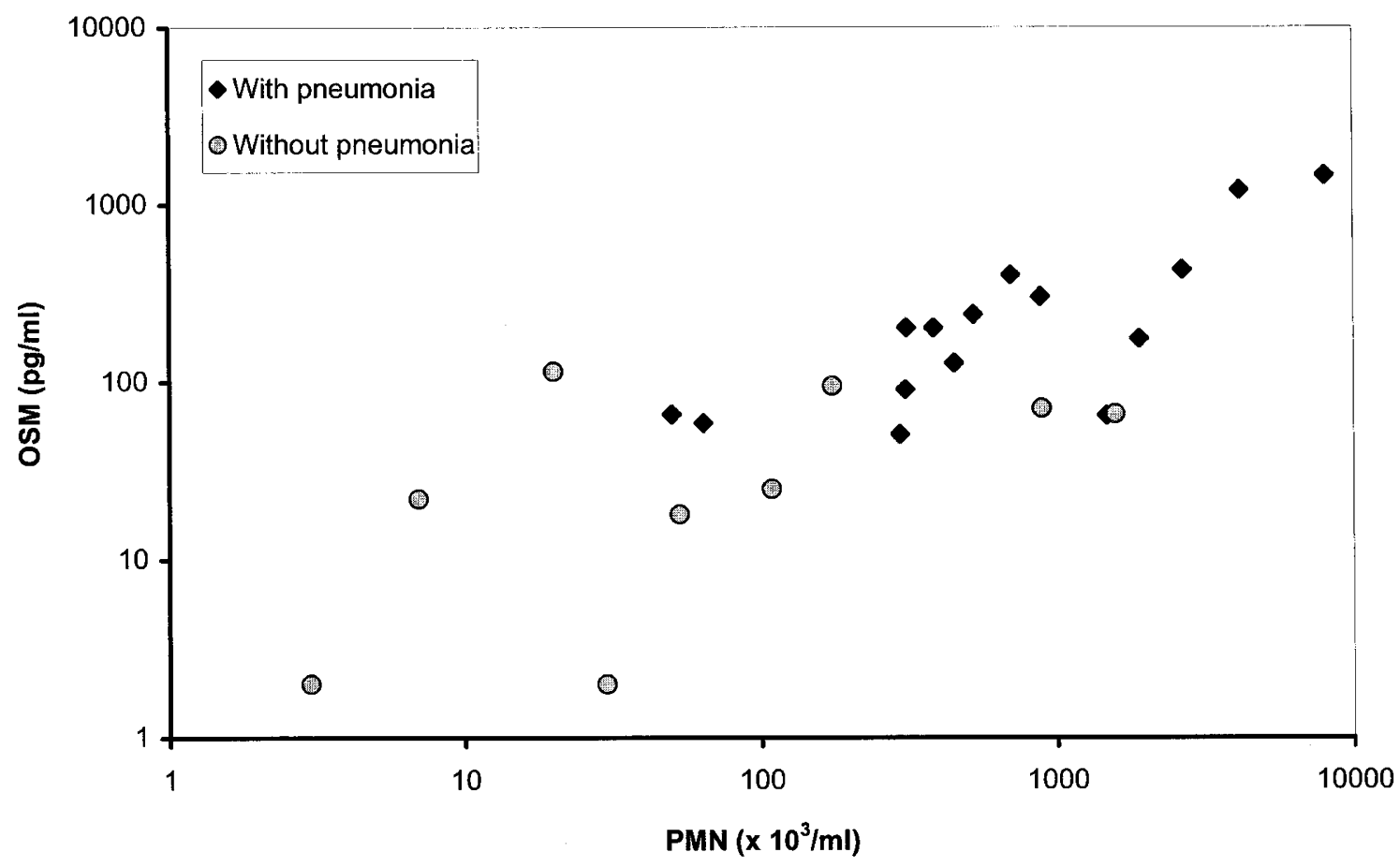

Figure 3.

Correlation between alveolar OSM concentrations and the absolute number of PMN in BAL fluid from the two patient groups (Spearman's correlation coefficient test [log scale]; $(\rho=0.74, p<0.001)$.

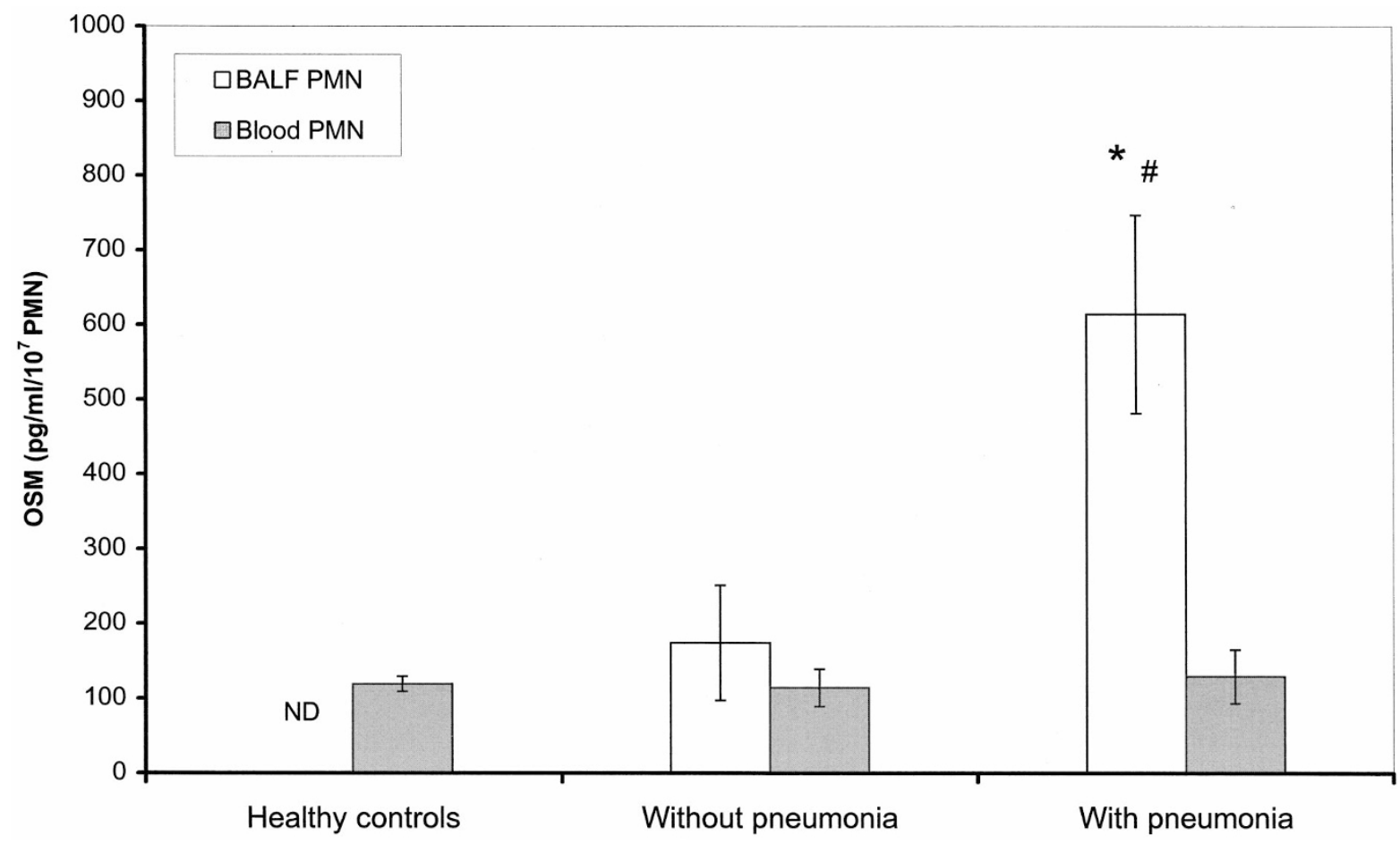

Figure 4.

Spontaneous OSM production by alveolar and blood PMN cultured for 18 hours. OSM was measured in the cell-free supernatants of cultured PMN from healthy controls and patients with ALI with or without pneumonia. * $p<0.01$ versus patients without pneumonia; $\# p<0.01$ versus autologous blood PMN; ND, not done.

OSM is first released from an intracellular stock. The recent description of an alternative OSM gene transcript potentially encoding an intracellular OSM protein further supports the existence of a rapidly mobi- lizable form of OSM (Voyle and Rathjen 2000). The second step involves de novo OSM synthesis by PMN, leading to sustained OSM release at inflammatory sites. In this study we observed spontaneous 
OSM production by alveolar PMN isolated from all of the patients, and especially from those with pneumonia. The trend toward a correlation with the $\mathrm{PaO}_{2} / \mathrm{FiO}_{2}$ ratio, but not with a more general index of pulmonary disease severity (SAPS), suggests that OSM production by highly purified alveolar PMN may play a role in the resolution of pulmonary inflammation. Spontaneous high OSM production may serve as a new marker of cell activation in this setting. Indeed, alveolar PMN are known to be locally activated, as reflected by CD11b and CD62L adhesion molecule expression and ROS production (Chabot et al, 1998; Chollet-Martin et al, 1996; Martin et al, 1991). PMN may thus have a dual role, both inducing and helping to repairing tissue lesions. Numerous mediators present within the alveoli, such as GM-CSF, INF $\gamma$, TNF $\alpha$, and bacterial products, can activate and/or prime PMN in vivo, leading to high spontaneous OSM production ex vivo (these mediators are the most potent OSM inducers in vitro) (Grenier et al, 1999). Indeed, BAL fluid supernatants from patients with pneumonia were able to stimulate OSM production by normal blood PMN (not shown). Moreover, mechanical stress such as that induced by adherence and transendothelial migration can also contribute to PMN activation. For example, we and others have shown that cytokine production by PMN is dependent on integrin-extracellular matrix interactions (Derevianko et al, 1996; Gaudry et al, 1997).

Unlike alveolar PMN, circulating PMN did not seem to be strong OSM producers. Spontaneous OSM production by blood PMN was normal in both groups of patients, and plasma OSM was undetectable in most cases. The five patients who had low but detectable levels of plasma OSM all had septic shock, as previously reported (Guillet et al, 1995). However, blood PMN are known to be activated during severe pneumonia, as reflected by the results of several functional tests based on adhesion, degranulation, and the oxidative burst (Chabot et al, 1998; CholletMartin et al, 1996; Martin et al, 1991). Our results thus suggest that PMN are not globally activated in these settings, but that certain functions are selectively activated. Levels of leukemia inhibitory factor, which shares certain properties with OSM, are increased in culture supernatants of whole-blood cells from patients with ALI (Gruson et al, 1998), suggesting that the mechanisms of OSM and leukemia inhibitory factor secretion by blood cells during ALI may differ.

Because endothelial cells have abundant OSM receptors, circulating OSM may play a role in initiating the inflammatory response by increasing adhesion molecule expression, PMN adhesion, and transmigration (Modur et al, 1997; Yao et al, 1996). In our patients, the normal plasma OSM levels and the OSM production by blood PMN ex vivo suggest that OSM is not involved in alveolar PMN recruitment. However, in the lung, OSM produced locally by PMN could act as an autocrine or paracrine proinflammatory mediator; indeed, OSM can trigger the release of phospholipase A2 in vitro (Haselmann and Goppelt-Struebe, 1997) and can induce the secretion of gp91phox protein, one of the NADPH oxidase components involved in
ROS hyperproduction by PMN in patients with ALI (Chollet-Martin et al, 1992; Hoidal et al, 1998).

As well as these proinflammatory properties, several recent in vivo and in vitro studies suggest that the main role of OSM is to attenuate inflammatory responses and to restore normal homeostasis after tissue injury and/or infection. In a mouse model, OSM administration inhibited lipopolysaccharide-induced TNF $\alpha$ production and increased IL-6 production, but did not affect IL-10 and IL- $1 \beta$ levels (Wallace et al, 1999). These in vivo findings are in keeping with the low TNF $\alpha$, IL-10, and IL-1 $\beta$ levels and the high IL-6 levels that we have found previously in BAL fluid from patients with ALI (Chollet-Martin et al, 1992, 1994, 1996), and suggest that OSM produced by alveolar PMN could modulate local production of these cytokines.

In vitro, OSM is also a potent modulator of the cytokines involved in the inflammatory response. In particular, OSM inhibits IL-8 and granulocyte-macrophage colony-stimulating factor production by lung fibroblasts (Richards et al, 1996). These two cytokines play a major role in the pathogenesis of $A L I$, and locally produced OSM might alter their production, particularly by alveolar PMN, through an autocrine effect. In addition to reducing levels of proinflammatory cytokines, OSM can induce the production of several major serine proteinase inhibitors by alveolar epithelial cells, such as $\alpha 1$-AT, $\alpha 1$ antichymotrypsin, and secretory leukocyte protease inhibitor (Boutten et al, 1998; Cichy et al, 1998b; Sallenave et al, 1997). Because $\alpha 1$-AT is a potent elastase inhibitor, OSM released by alveolar PMN could regulate the local activity of PMN-derived elastase via $\alpha 1$-AT synthesis by alveolar epithelial cells. Similarly, because $\alpha 1$ antichymotrypsin is an effective inhibitor of the NADPH oxidase in PMN, OSM-induced $\alpha 1$-antichymotrypsin synthesis by pulmonary epithelial cells may have a role in modulating ROS-based lung damage (Kilpatrick et al, 1992). Lastly, OSM can also induce the tissue inhibitor of metalloproteinase 1 by human alveolar epithelial cells (Sallenave et al, 1997) and fibroblasts (Richards et al, 1997; Varghese et al, 1999), both in vitro, and in an in vivo study using an adenovirus vector-expressing mouse OSM (Kerr et al, 1999).

In conclusion, these results demonstrate that high levels of OSM are produced locally during ALI and that PMN contribute to this local production. In addition to their potent proinflammatory effects mediated by cytokine, ROS, and protease secretion, PMN might also attenuate local inflammation in the lungs. Indeed, OSM release by alveolar PMN could help to restore homeostasis after lung injury and/or infection.

\section{Patients and Methods}

\section{Patients and Controls}

The 24 mechanically ventilated patients enrolled in the study were recruited from the medical intensive care unit of Bichat Hospital in Paris. Ten volunteer nonsmokers served as healthy controls. Informed consent was obtained from the closest relative of each patient 
and from the healthy controls. All procedures were in strict accordance with the ethical standards of our institution. Patients were included if pneumonia was suspected on the basis of the following criteria: new or persistent lung opacity on chest radiographs plus two of the following items: fever $>38.3^{\circ} \mathrm{C}$ or hypothermia $<36^{\circ} \mathrm{C}$, white blood cell count $>10,000 / \mathrm{mm}^{3}$ or $<$ $5,000 / \mathrm{mm}^{3}$, and a purulent endotracheal aspirate. Patients underwent fiberoptic bronchoscopy, and samples were obtained by means of protected specimen brushing and BAL. The patients also underwent blood sampling on the same day. Hypoxemic patients with $A L I$ had restricted fluid intake and underwent diuresis to maintain the intravascular volume at the lowest level consistent with adequate systemic perfusion (especially in patients with heart failure).

All of the patients were ventilated using a tidal volume targeted to maintain a plateau airway pressure less than $35 \mathrm{~cm}$ of water and permissive hypercapnia was tolerated. The fraction of inspired oxygen $\left(\mathrm{FiO}_{2}\right)$ was set to maintain arterial oxygenation saturation at 0.9. $\mathrm{FiO}_{2}$ was always higher than 0.6 , and therefore PEEP was required in only two patients. These settings were in keeping with current recommendations on ALI (Artigas et al, 1998). Because mechanical ventilation has been reported to modulate inflammatory mediator production in the lung, the following ventilatory parameters were recorded: tidal volume, PEEP, $\mathrm{FiO}_{2}$, duration of ventilation, and $\mathrm{PaO}_{2} / \mathrm{FiO}_{2}$ ratio.

Empiric antibiotic treatment was started when direct examination of BAL fluid showed that more than $5 \%$ of cells contained intracellular organisms, and was subsequently adapted to the results of bacterial identification and susceptibility testing. If less than $5 \%$ of cells contained intracellular organisms, antibiotics were given if hemodynamic status changed, gas exchanges worsened, and/or the patient's underlying condition was severe before the onset of signs of pneumonia; otherwise, antibiotic treatment was started after obtaining the results of protected specimen brushing or BAL culture. The main antibiotics used were glycopeptides, aminoglycosides, and $\beta$-lactam agents. None of the patients received corticosteroids or cytotoxic chemotherapy. The other drugs used were vasoactive agents, diuretics, sedatives, heparin, and sucralfate.

Each patient's hospital chart was reviewed as previously described; general disease severity was estimated using the SAPS, and lung injury severity was estimated using the lung injury score, which includes the extent of roentgenographic densities, the severity of hypoxemia, and the level of PEEP (Chollet-Martin et al, 1996). The number of organ dysfunctions (Fagon et al, 1993) was also recorded on the day of the investigations, together with the presence of sepsis or septic shock. All of the patients included in the study had a lung injury score of less than 2.5 and were thus free of the acute respiratory distress syndrome. Pneumonia was diagnosed when at least one bacterial species was present at a significant density in the cultured protected specimen brushing sample $\left(\geq 10^{3} \mathrm{cfu} / \mathrm{ml}\right)$ or
BAL fluid $\left(\geq 10^{4} \mathrm{cfu} / \mathrm{ml}\right)$, and/or when direct examination of BAL fluid yielded $\geq 5 \%$ cells containing intracellular organisms. The 24 ventilated patients were thus assigned to two groups: (1) patients with severe pneumonia $(n=15)$, and (2) patients without pneumonia $(n=9)$.

\section{BAL}

All of the patients underwent BAL: six 20-ml aliquots of sterile saline were aspirated with a hand-held syringe, in less than 3 minutes, using a standard technique (CholletMartin et al, 1996). The fluid recovered from the first aliquot was discarded. Subsequent aliquots were pooled and rapidly filtered through sterile gauze, and the cells were counted with a hemacytometer; cytospin preparations were used for differential counts and screening for intracellular microorganisms. BAL fluid was rapidly centrifuged $\left(1200 \times g\right.$ for 10 minutes at $\left.4^{\circ} \mathrm{C}\right)$ and the supernatants were stored at $-70^{\circ} \mathrm{C}$ until OSM assay.

\section{Immunocytochemical Staining of Intracellular OSM in BAL Cells}

Cytospin preparations of BAL cells were fixed in cold methanol/acetone. Cytospun cells were first incubated with normal horse serum and with a polyclonal rabbit antihuman-OSM antibody (200 $\mu \mathrm{g} / \mathrm{ml})$ (R\&D Systems, Abingdon, United Kingdom), followed by sequential incubation with a biotinylated antibody and alkaline phosphatase-labeled streptavidin, according to the manufacturer's instructions (Vectastain ABC kit; Vector Laboratories, Burlingame, United Kingdom). Staining was completed by incubation with a chromogen substrate solution containing levamisole to block leukocyte alkaline phosphatase activity (Fast red substance solution; DAKO, Carpinteria, California). Positive staining developed as a red reaction product. Cytospin preparations incubated with nonspecific rabbit immunoglobulin (R\&D Systems) served as negative controls.

\section{Alveolar PMN Isolation and Culture}

The BAL cell pellets were resuspended in PBS (Pharmacia, Uppsala, Sweden) supplemented with $2 \%$ heat-inactivated FCS (Biowittacker, Gagny, France). PMN were purified by a 20-minute incubation at $4^{\circ} \mathrm{C}$ with antihuman HLA class II-coated magnetic beads (Dynal, Oslo, Norway) to deplete B lymphocytes, activated T lymphocytes, and alveolar macrophages as previously described (Grenier et al, 1999). The purified alveolar PMN suspension was then adjusted to a density of $10^{7}$ cells $/ \mathrm{ml}$ in RPMl 1640 culture medium supplemented with $2 \mathrm{mmol} / /$ glutamine, antibiotics and $10 \%$ heat-inactivated FCS (Biowittacker). PMN were then cultured for 18 hours at $37^{\circ} \mathrm{C}$ with $5 \% \mathrm{CO}_{2}$ without exogenous stimuli. Cell-free PMN culture supernatants were then collected and stored at $-70^{\circ} \mathrm{C}$ until OSM assay. 


\section{Peripheral Blood PMN Isolation and Culture}

Blood PMN from healthy volunteers and patients were isolated and purified as previously described (Grenier et al, 1999). Briefly, after whole-blood sedimentation in medium containing 9\% Dextran T-500 (Pharmacia) and 38\% Radioselectan (Schering, Lys-lez-Lannoy, France), the leukocyte suspension was centrifuged on Ficoll-Paque medium (Pharmacia) and PMN were further purified ( $>99.5 \%$ ) by a 20 -minute incubation with pan antihuman HLA class II-coated magnetic beads. Purified PMN $\left(10^{7} / \mathrm{ml}\right)$ were then cultured for 18 hours at $37^{\circ} \mathrm{C}$ with $5 \% \mathrm{CO}_{2}$ as described above. Cell-free PMN culture supernatants were collected and stored at $-70^{\circ} \mathrm{C}$ until $\mathrm{OSM}$ assay.

\section{Plasma Preparation}

Blood was collected in sterile EDTA-treated vacuum tubes just before fiberoptic bronchoscopy and immediately centrifuged $(1,200 \times \mathrm{g}$ for 10 minutes $)$ at $4^{\circ} \mathrm{C}$. Plasma was stored at $-70^{\circ} \mathrm{C}$ until OSM assay.

\section{OSM Assay}

OSM was assayed in plasma, BAL fluid supernatants, and alveolar and blood PMN culture supernatants by using a commercial ELISA kit (Quantikine; R\&D Systems) following the manufacturer's instructions. The detection limit was $2.1 \mathrm{pg} / \mathrm{ml}$.

\section{Statistical Analysis}

All results are expressed as means \pm SEM. Group means were compared by using analysis of variance (ANOVA) followed by multiple comparison of means by Fisher's least significance procedure. $p \leq 0.05$ was considered to denote statistically significant differences. Paired comparisons between groups were made using Wilcoxon's paired test. Correlations were identified with Spearman's rank correlation coefficient test $(\rho)$.

\section{References}

Acute Respiratory Distress Syndrome (ARDS) Network (2000). Ventilation with lower tidal volumes as compared with traditional tidal volumes for acute lung injury and the acute respiratory distress syndrome. N Eng J Med 342:1301-1308.

Artigas A, Bernard GR, Carlet J, Dreyfus D, Gattinoni L, Hudson L, Lamy M, Marini JJ, Matthay MA, Pinsky MR, Spragg R, and Suter PM (1998) The American-European consensus conference on ARDS, part 2. Ventilatory, pharmacologic, supportive therapy, study design strategies, and issues related to recovery and remodeling. Acute respiratory distress syndrome. Am J Respir Crit Care Med 157:13321347.

Boutten A, Venembre P, Seta N, Hamelin J, Aubier M, Durand G, and Dehoux MS (1998). Oncostatin M is a potent stimulator of $\alpha 1$-antitrypsin secretion in lung epithelial cells: Modulation by transforming growth factor- $\beta$ and interferon. Am J Respir Cell Mol Biol 18:511-520.
Chabot F, Mitchell JA, Gutteridge JM, and Evans TW (1998). Reactive oxygen species in acute lung injury. Eur Respir $\mathrm{J}$ 11:745-757.

Chollet-Martin S, Jourdain B, Gibert C, Elbim C, Chastre J, and Gougerot-Pocidalo MA (1996). Interactions between neutrophils and cytokines in blood and alveolar spaces during ARDS. Am J Respir Crit Care Med 154:594-601.

Chollet-Martin S, Montravers P, Gibert C, Elbim C, Desmonts JM, Fagon JY and Gougerot-Pocidalo MA (1992). Subpopulation of hyperresponsive polymorphonuclear neutrophils in patients with adult respiratory distress syndrome. Am Rev Respir Dis 146:990-996.

Chollet-Martin S, Rousset F, Chastre J, Gibert C, Banchereau $\mathrm{J}$, and Gougerot-Pocidalo MA (1994). Cytokines in adult respiratory distress syndrome. Lancet 344:1440.

Cichy J, Rose-John S, and Pure E (1998a). Regulation of the type II oncostatin $M$ receptor expression in lung-derived epithelial cells. FEBS Lett 429:412-416.

Cichy J, Rose-John S, and Travis J (1998b). Oncostatin M, leukaemia-inhibitory factor and interleukin 6 trigger different effects on alpha1-proteinase inhibitor synthesis in human lung-derived epithelial cells. Biochem J 329:335-339.

Dehoux M, Fierobe L, Grenier A, Toueg ML, Malas V, Durand G, and Aubier M (1999). Elevated levels of oncostatin M and leukemia inhibitory factor in bronchoalveolar lavage fluid of patients with pneumonia. Am J Respir Crit Care Med 159: A104.

Derevianko A, D'Amico R, and Simms H (1996). Polymorphonuclear leukocyte (PMN)-derived inflammatory cytokinesregulation by oxygen tension and extracellular matrix. Clin Exp Immunol 106:560-567.

Donnelly SC, McGregor I, Zamani A, Gordon MWG, Robertson CE, Steedman DJ, Little K, and Haslett C (1995). Plasma elastase levels and the development of the adult respiratory distress syndrome. Am J Respir Crit Care Med 151:14281433.

Fagon JY, Chastre J, Novara A, Medioni P, and Gibert C (1993). Characterization of intensive care unit patients using a model based on the presence or absence of organ dysfunction and/or infection: The ODIN model. Intensive Care Med 19:137-144.

Gaudry M, Bregerie O, Andrieu V, El Benna J, GougerotPocidalo MA, and Hakim J (1997). Intracellular pool of vascular endothelial growth factor in human neutrophils. Blood 90:4153-4161.

Grenier A, Dehoux M, Boutten A, Arce-Vicioso M, Durand G, Gougerot-Pocidalo MA, and Chollet-Martin S (1999). Oncostatin M production and regulation by human polymorphonuclear neutrophils. Blood 93:1413-1421

Gruson D, Hilbert G, Juzan M, Taupin JL, Coulon V, Moreau JF, Gualde N, and Gbikpi-Benissan G (1998). Sequential production of leukaemia inhibitory factor by blood cell culture in patients with ARDS. Intensive Care Med 24:366-368.

Guillet C, Fourcin M, Chevalier S, Pouplard A, and Gascan H (1995). ELISA detection of circulating levels of LIF, OSM, and CNTF in septic shock. Ann N Y Acad Sci 762:407-412.

Haselmann J and Goppelt-Struebe M (1997). Glucocorticoids inhibit oncostatin $\mathrm{M}$-induced phospholipase A2 gene expression in human hepatoma cells. Cytokine 9:199-205. 
Hoidal JR, Xu P, Huecksteadt T, Sanders KA, Pfeffer K, and Sturrock AB (1998). Lung injury and oxidoreductases. Environ Health Perspect 106:1235-1239.

Jorens PG, De Jongh R, Bossaert LL, De Backer W, Herman AG, Pollet H, Bosmans E, Taupin JL, and Moreau JF (1996). High levels of leukaemia inhibitory factor in ARDS. Cytokine 8:873-876.

Kerr C, Langdon C, Graham F, Gauldie J, Hara T, and Richards CD (1999). Adenovirus vector expressing mouse oncostatin $M$ induces acute-phase proteins and TIMP-1 expression in vivo in mice. J Interferon Cytokine Res 19: 1195-1205.

Kilpatrick L, McCawley L, Nachiappan V, Greer W, Majumdar S, Korchak HM and Douglas SD (1992). $\alpha 1$-antichymotrypsin inhibits the NADPH oxidase-enzyme complex in phorbol ester-stimulated neutrophil membranes. J Immunol 149: 3059-3065.

Malik N, Kallestad JC, Gunderson NL, Austin SD, Neubauer MG, Ochs V, Marquardt H, Zarling JM, Shoyab M, and Wei CM (1989). Molecular cloning, sequence analysis, and functional expression of a novel growth regulator oncostatin $M$. Mol Cell Biol 9:2847-2853.

Martin TR, Pistorses BP, Hudson LD, and Maunder RJ (1991). The function of lung and blood neutrophils in patients with the adult respiratory distress syndrome: Implications for the pathogenesis of lung infection. Am Rev Respir Dis 144:254-262.

Modur V, Feldhaus MJ, Weyrich AS, Douglas DL, Prescott SM, Zimmerman GA, and Mcintyre TM (1997). Oncostatin M is a proinflammatory mediator; in vivo effects correlate with endothelial cell expression of inflammatory cytokines and adhesion molecules. J Clin Invest 100:158-168.

Pittet JF, Mackersie RC, Martin TR, and Matthay MA (1997). Biological markers of acute lung injury: Prognostic and pathogenetic significance. Am J Respir Care Med 155:11871205.
Ranieri VM, Suter PM, Tortorella C, De Tullio R, Dayer JM, Brienza A, Bruno F, and Slutsky AS (1999). Effect of mechanical ventilation on inflammatory mediators in patients with acute respiratory distress syndrome: A randomized controlled trial. JAMA 282:54-61.

Richards CD, Kerr C, Tanaka M, Hara T, Miyajima A, Pennica D, Botelho F, and Langdon CM (1997). Regulation of tissue inhibitor of metalloproteinase- 1 in fibroblasts and acute phase proteins in hepatocytes in vitro by mouse oncostatin M, cardiotrophin-1, and IL-6. J Immunol 159:2431-2437.

Richards CD, Langdon C, Botelho F, Brown TJ, and Agro A (1996). Oncostatin M inhibits IL-1 induced expression of IL-8 and granulocyte-macrophage colony-stimulating factor by synovial and lung fibroblasts. J Immunol 156:343-349.

Sallenave JM, Tremblay GM, Gauldie J, and Richards CD (1997). Oncostatin M, but not interleukin-6 or leukemia inhibitory factor, stimulates expression of alpha1-proteinase inhibitor in A549 human alveolar epithelial cells. J Interferon Cytokine Res 17:337-346.

Varghese S, Yu K, and Canalis E (1999). Leukemia inhibitory factor and oncostatin $\mathrm{M}$ stimulate collagenase-3 expression in osteoblasts. Am J Physiol 276:E465-471.

Voyle RB and Rathjen PD (2000). Regulated expression of alternate transcripts from the mouse oncostatin $M$ gene: Implications for interleukin-6 family cytokine. Cytokine 12: 134-141.

Wallace PM, MacMaster JF, Rouleau KA, Brown TJ, Loy JK, Donaldson KL, and Wahl AF (1999). Regulation of inflammatory responses by oncostatin M. J Immunol 162:5547-5555.

Yao L, Pan J, Setiadi H, Patel KD, and McEver RP (1996). Interleukin 4 or oncostatin $\mathrm{M}$ induces a prolonged increase in $\mathrm{P}$-selectin mRNA and protein in human endothelial cells. J Exp Med 184:81-92. 